\title{
Principles and features to define and describe arts interventions for people with dementia: A qualitative realist study
}

\author{
Emily Cousins ${ }^{\mathrm{a} *}$, Victoria Tischler ${ }^{\mathrm{b}}$, Claire Garabedian ${ }^{\mathrm{c}}$ and Tom Dening ${ }^{\mathrm{d}}$
}

${ }^{a}$ Division of Psychiatry and Applied Psychology, University of Nottingham, Nottingham, England; ${ }^{b}$ College of Nursing, Midwifery and Healthcare, University of West London, London, England; 'Association for Dementia Studies, University of Worcester, Worcester, England; ${ }^{d}$ Division of Psychiatry and Applied Psychology, University of Nottingham, Nottingham, England.

*Correspondence details for corresponding author: Emily Cousins, Room A10, Institute of Mental Health, University of Nottingham, Jubilee Campus, Triumph Road, Nottingham, NG7 2TU, emily.cousins@ @ottingham.ac.uk, 01157484327.

Professor Victoria Tischler: University of West London, St Marys Rd, London, W5 5RF, victoria.tischler@uwl.ac.uk, 02082094208

Dr. Claire Garabedian: Association for Dementia Studies, University of Worcester, Henwick Grove, Worcester. WR2 6AJ, c.garabedian@worc.ac.uk , 01905542738

Professor Tom Dening: Institute of Mental Health, University of Nottingham, Jubilee Campus, Triumph Road, Nottingham, NG7 2TU. Tom.Dening@ nottingham.ac.uk, 0115 8230421.

This work was supported by The Alzheimer's Society under Grant Ref: 225 (AS-DTC2014-031) 


\section{Principles and features to define and describe arts interventions for people with dementia: A qualitative realist study}

Background: There is currently no consensus regarding the definition and description of arts interventions for people with dementia. Developing a common language of classification will encourage reflection on artistic practice, support the evaluation and improvement of arts interventions, and enable their benefits to be communicated more effectively.

Methods: Using a qualitative framework derived from Taxonomy and Realist methodology, a literature review was undertaken to identify what key principles underpin arts interventions. This analysis was complemented by focus groups and workshops incorporating the lived experience of carers, artists, practitioners and care staff.

Results: Nine principles were identified as elements present in person-centred arts interventions for people with dementia: Animation, Transcendence, Selfhood, Humanity, Expression, Connection, Possibility, Involvement, Awareness.

Conclusions: It is possible to identify the component parts of arts interventions for people with dementia. These principles form an empirical basis for understanding how arts interventions work, while still respecting their individual nature.

Keywords: arts; dementia; intervention; principles; taxonomy 


\section{Introduction}

The arts support wellbeing for people living with dementia, offering a positive range of benefits (Mental Health Foundation, 2011; All-Party Parliamentary Group on Arts, Health and Wellbeing, 2017). For example, music can improve remote memory, mood and general cognition (Särkämö et al., 2014); dance enables aerobic health and dexterity, as well as expression, emotion and presence (Coaten, 2011); poetry can provide opportunities for catharsis and challenge (Petrescu et al., 2014). There is an innate human appetite for creativity (Zaidel, 2014); to deprive older people access to this enrichment is unethical. The arts will not be appropriate for every person's care, but they frequently address the holistic needs of people with dementia by making meaning and creating connection.

However, the evidence base for the arts and dementia needs to be strengthened. Studies are often small scale, without robust methodology (Young et al., 2016). The arts can appear unquantifiable, and we currently lack the conceptual and measurement tools to look beneath the surface to explore why one intervention is effective and another is not. It is also possible that diverse arts practices may have some common elements that underlie how they 'work'.

The purpose of this study is to begin to develop a consistent model to define and describe arts interventions for people with dementia. Understanding the component parts of arts interventions will support reflections on artistic practice; allow the impact of the arts to be communicated more effectively to funders, carers and the wider population; and enable better quality research to be undertaken. Thus, the research objective is to contribute to the devising of a common language for identifying, naming and labelling arts practice for people living with dementia. In this study, we have taken a unified view of the arts as a whole to be a helpful starting point. We attempt to develop a map of the underlying structure of this complex field, by suggesting shared or 
generalisable principles of arts practice for people with dementia. This preliminary description will need to be complemented by subsequent research that distinguishes between art forms, artistic approaches or applications and arts professions for example, in relation to dementia.

Matarasso (2010) articulates an important caution in an assessment of arts impact, which is highly relevant for this study. He warns of reductive assumptions made by those who imagine 'the arts as a kind of vending machine into which they can tip some money, punch in the right numbers and collect the selected outcome' (p2). In attempting to define and describe arts interventions, the nuance and individuality of each activity must still be observed. Furthermore, the fluidity of artistic practice, and the social or relational dynamic of the arts (Camic et al., 2016) add layers of complexity. Therefore findings from this study are an emergent theoretical model requiring further testing.

This classification will recognise common denominators of arts interventions, while allowing for individual approaches by practitioners and the maintenance of personhood formed of "recognition, respect and trust" (Kitwood, 1997, p8). Kitwood (1997) identified five primary psychological needs required by all people: Attachment, Comfort, Identity, Occupation, Inclusion. The field of arts and dementia should consider what unique needs might be met through an arts intervention and also how arts participation can work for people living with the condition.

\section{Methods}

\section{Methodological approach and theoretical framework}

A realist approach (Pawson et al., 2004; Pawson et al., 2005) was used to design this study. Realist review encourages iterative and flexible investigation that incorporates 
real world voices, while ensuring research quality by maintaining systematic values of 'relevance' and 'rigour' (Pawson et al., 2005). Realist methodology emphasizes context and complexity - two elements that are especially pertinent for multi-disciplinary arts interventions.

This study is also underpinned by theoretical approaches drawn from taxonomy, the science of classification. Bailey (1994) argues that classification is a central process to our lives, without which 'there could be no advanced conceptualization, reasoning, language...or social science research' (p1). Beyond identifying characteristics, taxonomy includes 'the organization of knowledge in a manner that can be used by the wider community' (Godfray and Knapp, 2004, p560). Similarly, this study aims to produce useful information for practitioners, funders and researchers of arts interventions for people with dementia. Taxonomy must also 'pay great attention to the end-user' (Godfray and Knapp, p568) - complementing the realist ethos of including real-world stakeholders. Snyder (1982) cautions that 'it is explanation rather than taxonomy which should play the leading role' (p512). This classification must therefore attempt to explain its mechanisms, as well as map them. Tsing (2010) highlights the relationship between naming and noticing: 'through naming, we notice the diversity of life. Taxonomy was once closely allied with drawing, another art of noticing' (p192). In this way, taxonomy and the arts have a historic compatibility.

There were three parts to this study: a literature review, three focus groups and two Nominal Group Technique (NGT) workshops.

\section{A systematic, realist literature review}

The literature review applied a blend of systematic and realist approaches. A purely systematic review was not appropriate given the grey literature to be incorporated from the arts and dementia field: 'realist review is much more likely to make use of grey 
literature' (Pawson et al., 2005, p29). However, systematic principles of comprehensiveness and transparency were employed.

A scoping search was undertaken across four databases: CINAHL, Medline, AMED and PsycINFO.

[Table 1 here]

Its purpose was to gather the many types of arts intervention for people with dementia; a function of taxonomy. Articles were retained that listed characteristics, features or qualities of arts approaches. After screening abstracts and removing duplicates 748 articles remained. A sample of the literature was then read to formulate a research question for the review (Booth, Papaioannou and Sutton, 2012). This reading identified a research gap in the published work regarding the component parts of arts interventions. In particular, how arts interventions produce their effects or, in other words, the shared underpinning principles by which they operate. Therefore, the following research question was formed: 'What underpinning principles guide arts interventions for people with dementia'?

The remaining articles were then re-screened to identify a selection of core literature for the review. In order to encompass the grey literature, no restrictions regarding year of publication, journal type or country of origin were imposed. Due to practical constraints, only English language texts were included. This second screening resulted in 29 articles. Hand searching, snowballing and reports from real world organisations and practitioners increased the final selection to 38 sources [Figure 1]. [Figure 1 here]

The core literature was coded for implicit and explicit components of arts interventions for people with dementia [Table 2]. Explicit components were clearly 
stated as features of arts interventions in the literature; implicit components were inferred based on description. The majority of the codes identified were explicit. These codes were then thematically analysed (Braun and Clarke, 2006) and grouped into a first iteration of the principles, supplemented by descriptive features drawn from the accompanying text.

[Table 2 here]

\section{Focus groups and Nominal Group Technique workshops}

Focus groups addressed the gaps in the published literature. Realist review values personal expertise as knowledge (Pawson et al., 2004). The focus groups allowed data extraction from the literature to be verified, while also enabling new ideas and stakeholders to be included. Questions were exploratory and open-ended. Examples include: 'What are the essential ingredients of an arts activity for people with dementia?' and 'How do arts activities differ to other activities?' Interview transcripts were coded deductively, led by the first iteration of the principles and features developed in the literature review. Additionally, the transcripts were coded inductively (Braun and Clarke, 2006) to allow new themes to emerge. The principles and features were refined a second time to include these findings.

The Nominal Group Technique (NGT) workshops emerged from the focus groups as a final stage of data collection and group decision-making. Their purpose was to facilitate more specific discussion and to directly test the principles that had been developed so far. Jones and Hunter (1995) note that 'the nominal group technique focuses on a single goal (for example, the definition of criteria...) and is less concerned with eliciting a range of ideas' (p378). This process gives each participant an equal opportunity to contribute. Participants were asked to generate their own ideas for principles of arts interventions, as well as to comment on those already produced by the 
researcher. Each participant was invited to share these with the group, and then discuss and clarify these points collectively. Again transcripts were coded, analysed, and the principles and features were honed a third time.

\section{Research participants}

The focus groups and NGT workshops incorporated a range of participants, including family carers, care staff, activity co-ordinators, artists, practitioners, academics, arts administrators and one person with dementia [see Table 3 below]. These participants were recruited by email and personal contact through professional and carers' networks, arts and care organisations and arts programmes. The inclusion criteria for participation were expertise and lived experience of dementia or the arts. This variety of perspectives enabled the diversity of this multi-disciplinary work to be captured. Three focus groups and two NGT workshops were facilitated by the researcher (EC), balancing practical constraints with a saturation point regarding findings. Some participants attended a focus group and an NGT workshop creating a natural progression and providing some continuity. Informed consent was sought from participants (Ethics Reference No: J18032016 SoM).

[Table 3 here]

\section{Results}

\section{Principles of arts interventions for people with dementia}

Following data collection, coding and thematic analysis from the literature review, focus groups and NGT workshops, nine principles [Table 4] and accompanying descriptive features of arts interventions for people with dementia were identified [Table 5].

Principles are creative values that define and describe the component parts of person-centred arts interventions. Principles transform the art form into an arts 
intervention designed to meet the needs of a person with dementia. Principles are elements present in, or enabled by, arts interventions. They operate within the context of dementia, and are triggered by the artistic medium and its delivery including the approach of a practitioner.

The generative model of realist review determines what works for who in a complex intervention. This model states that to 'infer a causal outcome $(\mathrm{O})$ between two events (X and $\mathrm{Y})$ one needs to understand the underlying generative mechanism $(\mathrm{M})$ that connects them and the context (C) in which the relationship occurs' (Pawson et al., 2004, p2). Mechanisms are the invisible force, acting upon a given context, which produce a specified outcome. Principles of arts interventions could be thus interpreted as mechanisms. The principles sit between the context, which in this instance is provided by the arts activity and the individual with dementia, and the outcome, which is a positive experience or other benefit from contact with the arts activity or art form. [Table 4 here]

\section{Descriptive features of arts interventions}

The supplementary features of arts interventions are individual descriptions that articulate the principles. They add detail to the principles offering an explanation of arts interventions that extends beyond simple classification. The words to label the features were identified in the literature review, or from the coding of the focus group and NGT transcripts. For accurate comparison, a list of ten features was attributed to each principle on the basis of their salience. [Table 5 here]

\section{Discussion}

Main findings 
We found evidence of nine active principles that appear to operate in arts interventions for people with dementia: Animation, Transcendence, Selfhood, Humanity, Expression, Connection, Possibility, Involvement, Awareness. These principles, each underpinned by a set of contributory features, function ascomponents that participants might experience during an arts intervention.

There was agreement and disagreement between the literature review, focus groups and NGT workshops data, hence the three iterations of the principles and their features. For example the principle of Connection was initially named Interaction. However, members of focus group 3 made a compelling argument regarding the importance of connection, which also implies interaction, but works as a more personcentred description. One participant said: 'I think connectivity and re-connecting people with their past, and their identity, is what music certainly does for me' [Musician, care staff trainer, parent with dementia]. As a result, Connection became a principle, and Interaction its feature.

The Dementia and Imagination project similarly used a realist methodology to identify the active ingredients of effective visual art interventions for people with dementia (Windle et al., 2016). The project handbook for use by artists and session facilitators likewise identifies engagement, self-expression, social interaction and creativity as fundamental mechanisms for the visual arts - and additionally indicates the importance of inspiration and celebration within arts interventions (Parkinson, Windle and Taylor, 2017).

\section{Principles as personal needs}

The principles describe human needs that may be fulfilled by the arts - needs that are particularly important for people with dementia. Kitwood's (1997) identification of five basic human needs (Attachment, Comfort, Identity, Occupation, Inclusion) has allowed 
a different type of language to emerge within the discourse of dementia care, which supports the description of psychosocial interventions. The principles echo Kitwood's vocabulary of sensitivity, and extend the description of such concepts to the context of the arts. A consistent theme in the focus groups was the philosophical recognition of art as essential - a human need. One carer remarked that 'They make us human. Without the arts we're not human beings' [Carer 1, focus group 2]. There is a natural synergy therefore between the descriptive work of Kitwood, designed to protect personhood, and the arts as activities to enable humanity. Furthermore, Kitwood's (1997) work on malignant social psychology identified a number of negative behaviours that undermine personhood. He therefore laid a foundation in dementia care that recognised the power of labelling and noticing. The principles respond to this precedent of classification, but in a positive way by defining and describing creative values to incorporate, rather than avoid.

\section{Principles are descriptive not prescriptive}

Conceptualising arts interventions in this way - as a set of high level principles rather than fixed specifics - enables description without prescriptiveness. As de Medeiros and Basting (2014) urge, 'We must move away from disciplinary boundaries and instead focus on better understanding what various cultural arts interventions comprise' (p351). These principles generate balance by allowing subjectivity and interpretation, key features of arts practice, within the framework of a common language.

Perspectives did vary between data sources and stakeholders. One example relates to the arts intervention as a process of exploration, or an opportunity to create a product. Beard (2011) similarly notes this tension between process and product in her systematic review. However, the principles can complement each other to support different approaches within arts interventions in order to meet personal needs. 


\section{Principles in action: The example of balancing product and process}

The principle of Possibility includes 'product' as a feature, and illustrates the achievement that can be felt by people with dementia when afforded the opportunity to build new skills or recapture existing abilities. This sense of accomplishment may be compounded by making a product. Ullán et al. (2013) note that within one arts and education programme, 'the participants received the works they had made' (p432), which supports the principle of Selfhood by boosting esteem.

In focus group 2, there was a belief that a product could help to generate purpose: 'We...made pots... and that's very therapeutic...And very stimulating, because you end up with an object. That you can take home.' [Carer 2]; 'A friend of mine...she'd made some little model and painted it and done. And was very proud of it' [Carer 3].

This was echoed by a participant in focus group 3, who is both a musician and a carer, stressing the importance of performance '...to showcase what they're doing.' [Musician, parent with dementia]. This interaction with the outside world also engages the principles of Connection and Awareness.

However, while 'product' is clearly important, the data also indicated that 'process' is another feature crucial to artistic practice, present in the principle Humanity. Hanneman (2006) stressed the importance of the creative process. In the context of dance and movement, Vella-Burrows and Wilson (2016) discuss the links between 'enabling flow' (process) and being in the moment, both features in the principle of Transcendence. Furthermore, the literature recommends arts interventions be failure-free environments (Phillips and Conn, 2009) - which arguably favours a process focussed approach

In focus group 1, an artist explored the possible tension between process and product, and illustrated how cohesion can be found between these features: 
... you begin to think that the idea of a process is as important as the finished product sometimes, and how you balance that. And so, even if someone hasn't completely finished it, sometimes we realise that residents do want it finished don't they? They would like a finished piece of work. But also, being open as an artist, that it's not just getting to the end of it [Artist 1].

This demonstrates how the professional experience of a practitioner can mediate the principles in action, and use them to deliver an arts intervention that maintains personhood.

\section{Strengths and limitations of the study}

This study experienced some of the same methodological challenges that are acknowledged in other arts and dementia research, for example the difficulty in identifying their active ingredients (Windle et al., 2017). In response, this study pursued a blended methodology, incorporating elements of systematic and realist review. The authors acknowledge the tension that could exist in attempting to identify the component parts of arts interventions, with the assumption of generalisability this might imply, given the arts are typified by subjective experience (Jaaniste, 2011).

However, part of strengthening the evidence base is to experiment with new and different methodological approaches and discover appropriate theoretical models for research. A realist approach was recently supported by the All-Party Parliamentary Group on Arts, Health and Wellbeing Inquiry Report (2017). The method of this study remained robust and is recounted clearly, though qualitative coding and analysis by a sole researcher dilutes the study's authority. A realist approach permits the inclusion of grey literature, which necessarily and positively enabled diverse real world perspectives to be included. 
As a consequence, the sources identified for the literature review differed in quality and robustness according to the standards of peer-reviewed research. By way of a defence, these provisional findings have been tested, verified and refined at each stage of the study in dialogue with a variety of stakeholders, as outlined in Table 3 . These voices of experience and expertise offered knowledge and scrutiny to temper the more informal texts.

The concept of taxonomy has proved a divisive term in some focus groups and NGT workshops. While this concept is helpful as a tool for classification, not all stakeholders have responded positively to the taxonomy model as an appropriate means of definition for arts interventions. One participant in an NGT workshop stated 'I'm struggling with the idea of it being a taxonomy' [NGT workshop 2]. It remains an open question as to whether 'taxonomy' represents the best word for the task of defining and describing arts interventions. This warrants exploration in future research.

Although the focus groups and NGT workshops were diverse, the number of participants was still relatively small (30 different participants in total). Therefore the findings may not be representative. So far, the principles exist only as a theory. The next phase of research will be to test the principles within the context of a real world arts intervention to ensure validity and reliability, particularly across arts modalities and dementia diagnoses. Further iterations or replication of the study may change the number or name of the principles and their features. Accordingly, these findings are provisional and require further exploration within the wider arts and dementia community.

\section{Implications for stakeholders}

The results and findings from this study have implications for practitioners, funders and researchers of arts interventions for people with dementia. 
For artists, practitioners, care staff and carers, these principles offer a direction for evidence-based best practice when delivering arts interventions for people with dementia. While definition and description imply a retrospective interpretation of content, the principles can equally be used to plan and prepare arts interventions. This knowledge of component parts can be used to inform the content and approach of arts activities. The principles are designed to support individual delivery and decisionmaking, recognising that arts practice will be applied differently depending upon the needs of each participating person with dementia. Future research by our group, a case study of music therapy, will explore how the principles might be implemented into practice - observing the context of both music as an art form, and therapy as an artistic approach and profession.

For funders and commissioners, these principles and features can form the basis for service specification descriptions and arts intervention outcomes, impacts and benefits for people with dementia. The definition and description of the principles will bring greater clarity to bid applications by helping to illustrate the effects that the arts can have for people with dementia, and will guide investment towards providers who offer reflective and high quality interventions.

For researchers, these principles and features can be used to define and describe arts interventions for people with dementia, supporting evaluation and analysis. The principles avoid a reductive classification of art, allowing space for personal interpretations of meaning and connection. Further research is required to determine whether the principles have application beyond the arts and dementia. They suggest art is fundamental to humanity, and in some respects a person-centred approach disregards diagnosis. Yet the principles also capture the essence of meaning and connection so particular about the relationship between dementia and art. 


\section{Conclusion}

The principles and their accompanying features open-up the discussion of classifying and explaining the component parts of arts interventions for people with dementia. This study has shown that it is possible to identify the underpinning mechanisms of arts interventions. We have defined and described their values using labels that articulate the content and context of these interactions. This helps to demystify art and sets out a framework for a common language of understanding. Noticing and naming the personal needs that can be met by arts interventions could enable more instances of meaning and connection for people with dementia and the provision of better care.

\section{Acknowledgements}

The authors would like to thank the focus group and NGT workshop participants who generously gave their time and ideas, as well as those who helped to host them in meetings. This work was funded by The Alzheimer's Society under Grant Ref: 225 (AS-DTC-2014-031), the TAnDem (The Arts and Dementia) Doctoral Training Centre at the Universities of Nottingham and Worcester, England.

Word count: Body of article: 3861, Total document: 6982 


\section{References}

All-Party Parliamentary Group on Arts, Health and Wellbeing (2017). Creative Health: The Arts for Health and Wellbeing. London: APPG on Arts, Health and Wellbeing.

Bailey, K. (1994). Typologies and Taxonomies. An introduction to classification techniques. Thousand Oaks: Sage Publications

Baines, P. (2007). Nurturing the heart: creativity, art therapy and dementia. Alzheimer's Australia, Tasmania.

Beard, R. L. (2011). Art therapies and dementia care: a systematic review. Dementia, 11(5): pp. 633-656. doi: 10.1177/1471301211421090

Beat it Percussion (2015). Positive Outcomes of Drumming For People Living with Dementia. Report of Pilot Project in Herefordshire and Worcestershire. Beat it Percussion.

Behrman, S., et al. (2014). Considering the senses in the diagnosis and management of dementia. Maturitas,77(4): 305-310.

Braun, V. and Clarke, V. (2006). Using thematic analysis in psychology. Qualitative Research in Psychology, 3:2, pp.77 - 101. doi: 10.1191/1478088706qp063oa

Booth, A. and D. Papaioannou, A. Sutton (2012). Systematic approaches to a successful literature review. London: Sage Publications

Byers, A. (2011). Visual aesthetics in dementia. International Journal of Art Therapy: Inscape, 16(2), pp.81-89.

Caddell, L. S. and L. Clare (2011). Interventions supporting self and identity in people with dementia: A systematic review. Aging \& Mental Health, 15(7), pp.797-810

Camic, P.M., and E.L.Baker, V.Tischler. (2016). Theorizing how art gallery interventions impact people with dementia and their caregivers. Gerontology, 56 (6), pp. 1033-1041. doi: 10.1093/geront/gnv063

Coaten, R. (2011). Dance movement psychotherapy in dementia care. In H. Lee \& T. Adams (Eds.), Creative Approaches in Dementia Care (pp. 73-90). New York: Palgrave Macmillan

Cowl, A. L. and J. E. Gaugler (2014). Efficacy of creative arts therapy in treatment of Alzheimer's disease and dementia: a systematic literature review. Activities, Adaptation \& Aging, 38(4), pp.281-330.

Crossick, G. and P. Kaszynska (2016). Understanding the value of arts \& culture. The AHRC Cultural Value Project. Arts and Humanities Research Council, Swindon.

de Medeiros, K. and A. Basting (2014). Shall I compare thee to a dose of donepezil?": cultural arts interventions in dementia care research. Gerontologist, 54(3), pp. 344-353. doi: 10.1093/geront/gnt055

Duffin, C. (2013). Bringing memories to life. Nursing Older People, 25(3), pp.28-29. 
Godfray, H. and S. Knapp (2004). Introduction. Taxonomy for the twenty-first century. Philosophical Transactions of the Royal Society B: Biological Sciences, 359(1444), pp.559-569 . doi: 10.1098/rstb.2003.1457

Habron, J. (2013). 'A conversation without words'--reflections on music therapy and dementia. Dementia, 12(1), pp.3-6.

Hannemann, B. T. (2006). Creativity with dementia patients: Can creativity and art stimulate dementia patients positively?, Gerontology, 52(1), pp. 59-65. doi: $10.1159 / 000089827$

Holm, A. K., et al. (2005). Dementia: involving patients in storytelling--a caring intervention. A pilot study. Journal of Clinical Nursing, 14(2), pp.256-263.

Hulme, C., et al. (2010). Non-pharmacological approaches for dementia that informal carers might try or access: A systematic review. International Journal of Geriatric Psychiatry, 25(7), pp.756-763.

Jaaniste, J. (2011). Dramatherapy and dementia care. In H. Lee \& T. Adams (Eds.), Creative Approaches in Dementia Care (pp. 54-72). New York: Palgrave Macmillan.

Jones, J. and Hunter, D. (1995). Consensus methods for medical and health services research. BMJ, 5; 311 (7001), pp.376-80. doi: 10.1136/bmj.311.7001.376

Killick, J. and K.Allan (2011). Creative communication at the end of life. In H. Lee \& T. Adams (Eds.), Creative Approaches in Dementia Care (pp. 230-247). New York: Palgrave Macmillan. Kitwood, T. (1997). Dementia Reconsidered. The person comes first. London: Open University Press

Kontos, P. and W. Martin (2013). Embodiment and dementia: exploring critical narratives of selfhood, surveillance, and dementia care. Dementia, 12(3), pp.288-302.

Marshall, M. J. and S. A. Hutchinson (2001). A critique of research on the use of activities with persons with Alzheimer's disease: a systemic literature review. Journal of Advanced Nursing, 35(4), pp.488-496.

Matarasso, F. (2010) Full, free and equal: On the social impact of participation in the arts. Knowle West Media Centre, Bristol 22 September 2010.

Mental Health Foundation (2011). An Evidence Review of the Impact of Participatory Arts on Older People. Edinburgh: Mental Health Foundation.

Morley, J. E., et al. (2014). Meaningful activities in the nursing home. Journal of the American Medical Directors Association, 15(2), pp.79-81.

Mottram, P. (2003). Art therapy with clients who have dementia. Dementia: The International Journal of Social Research and Practice, 2(2), pp.272-277.

Parkinson, C., Windle, G., Taylor, K. (2017). Dementia \& Imagination. Research Informed Approaches to Visual Art Programmes. Dementia and Imagination. Available online: http://www.artsforhealth.org/resources/dementia-and-imagination.pdf [Accessed on 25th April 2018] 
Pawson, R. and T. Greenhalgh, G. Harvey, K. Walshe (2005) Realist review - a new method of systematic review designed for complex policy interventions. Journal of Health Services Research \& Policy, 10, pp.21-34. doi: 10.1258/1355819054308530

Pawson, R. and T. Greenhalgh, G. Harvey, K. Walshe (2004) Realist synthesis: an introduction. ESRC Research Methods Programme, University of Manchester.

Petrescu, I. and K. MacFarlane, R Ranzijn (2014). Psychological effects of poetry workshops with people with early stage dementia: an exploratory study. Dementia, 13(2), pp.207-215. doi: 10.1177/1471301212456279

Phillips, L. J. and V. S. Conn (2009). The relevance of creative expression interventions to person-centered care. Research in Gerontological Nursing, 2(3), pp.151-152. doi: 10.3928/19404921-20090527-03

Price, K. A. and A. M. Tinker (2014). Creativity in later life. Maturitas, 78(4),pp. 281286.

Rancour, P. and T. Barrett (2011). Art interpretation as a clinical intervention toward healing. Journal of Holistic Nursing, 29(1), pp.68-80.

Rylatt, P. (2012). The benefits of creative therapy for people with dementia. Nursing Standard, 26(33), pp.42-47.

Särkämö, T., and M. Tervaniemi, S. Laitinen, A. Numminen, M. Kurki, J.K. Johnson, P. Rantanen, (2014). Cognitive, Emotional, and Social Benefits of Regular Musical Activities in Early Dementia: Randomized Controlled Study. Gerontologist, 54 (4): pp. 634-650. doi: 10.1093/geront/gnt100

Sixsmith, A. and G. Gibson (2007). Music and the wellbeing of people with dementia. Ageing \& Society, 27(1), pp.127-145.

Snyder, A. (1982). Taxonomy and Theory. Proceedings of the Biennial Meeting of the Philosophy of Science Association. Volume Two: Symposia and Invited Papers, pp.512521. Chicago: University of Chicago Press

Tsing, A. (2010). Arts of Inclusion, or How to Love a Mushroom. Manoa, 22 (2), pp.191 - 203. Tuppen, J. (2012). The benefits of groups that provide cognitive stimulation for people with dementia. Nursing Older People, 24(10), pp.20-24.

Ullán, A. M., and M. Belver, M. Badía, C. Moreno, E. Garrido, J. Gómez-Isla, E. Gonzalez-Ingelmo, J. Delgado, I. Serrano, C. Herrero, P. Manzanera, L. Tejedor (2013). Contributions of an artistic educational program for older people with early dementia: an exploratory qualitative study. Dementia, 12(4), pp.425-446. doi: $10.1177 / 1471301211430650$

Vella-Burrows, T. and L. Wilson (2016). Remember to Dance. Evaluating the impact of dance activities for people in different stages of dementia. Sidney De Haan Research Centre for Arts and Health. Canterbury: Canterbury Christ Church University

Verity, J. and H. Lee (2011). Reigniting the human spirit,. In H. Lee \& T. Adams (Eds.), Creative Approaches in Dementia Care (pp. 16-31). New York: Palgrave Macmillan 
Windle, G., and S.Gregory, T. Howson-Griffiths, A.Newman, D.O'Brien, A.Goulding (2017). Exploring the theoretical foundations of visual art programmes for people living with dementia. Dementia. doi: 10.1177/1471301217726613. [Epub ahead of print]

Windle, G. and S. Gregory, A. Newman, A. Goulding, D. O’Brien, C. Parkinson, (2014). Understanding the impact of visual arts interventions for people living with dementia: a realist review protocol. Systematic Reviews, 3:91, pp. 1-7. doi:

10.1186/2046-4053-3-91

Windle, G., Newman, A., Burholt, V., Woods, B., O’Brien, D., Baber, M., et al. (2016) Dementia and Imagination: a mixed-methods protocol for arts and science research, BMJ Open, 2016;6:e011634. doi: 10.1136/bmjopen-2016-011634

Woods, M. and S. Jury (2010). Striking a positive note. Interview by Sue Learner. Nursing Standard, 25(2), pp.24-25.

Young, R., and P.M.Camic, V.Tischler (2016). The impact of community-based arts and health interventions on cognition in people with dementia: a systematic literature review. Aging \& Mental Health, 20 (4), pp.337-351. doi: 10.1080/13607863.2015.1011080

Zaidel, D.W. (2014). Creativity, brain, and art: biological and neurological considerations. Frontiers in Human Neuroscience, 8:389, pp. 1- 9. doi: 10.3389/fnhum.2014.00389

Zeiler, K. (2014). A philosophical defense of the idea that we can hold each other in personhood: intercorporeal personhood in dementia care. Medicine, Health Care \& Philosophy, 17(1), pp. 131-141.

Zinn, L. (2005). Activities for dementia care: unlocking what remains. Nursing Homes: Long Term Care Management, 54(2), pp. 24-28. 


\section{Tables with captions}

Table 1: Search terms used for scoping search in literature review

\begin{tabular}{|l|}
\hline Theatre AND dementia; \\
\hline Arts AND dementia; \\
\hline Therapy AND dementia; \\
\hline Music AND dementia; \\
\hline Singing AND dementia; \\
\hline Creativ* AND dementia; \\
\hline Dance AND dementia; \\
\hline Performing AND dementia; \\
\hline Art* AND dementia; \\
\hline Museum AND dementia; \\
\hline Gallery AND dementia; \\
\hline Activit* AND dementia; \\
\hline Arts AND Alzheimer's. \\
\hline
\end{tabular}


Table 2: Components of arts interventions for people with dementia coded in the

\section{literature}

\begin{tabular}{|c|c|}
\hline Author & $\begin{array}{l}\text { Components of arts interventions for people with dementia coded in the } \\
\text { literature }\end{array}$ \\
\hline $\begin{array}{l}\text { Baines } \\
(2007)\end{array}$ & $\begin{array}{l}\text { Creativity, Community, Respect, Identity, Potential, Expression, Satisfaction, } \\
\text { Communication, Pleasure, Sustenance, Transcendence, Positive ageing, } \\
\text { Possibilities, Self-worth, Safety, Nurturing, Choice, Non-judgemental, } \\
\text { Conversation, Emotions. }\end{array}$ \\
\hline $\begin{array}{l}\text { Beard } \\
(2011)\end{array}$ & $\begin{array}{l}\text { Enrichment, Product, Process, Person-centred, Meaning, Creative, Manage } \\
\text { behaviours, Empowerment, Expression, Relaxation, Hope, Healing, Pleasure, } \\
\text { Discovery, Self-worth, Validate, Stimulation, Relationships, Interaction, } \\
\text { Community, Reminiscence, Pride, Dignity, Strengths, Cohesion, Increase mood, } \\
\text { Multi-modal, Doing, Continuity, Engaging, Tailored, Cultural awareness. }\end{array}$ \\
\hline $\begin{array}{l}\text { Beat it } \\
\text { Percussion } \\
(2015)\end{array}$ & $\begin{array}{l}\text { Involvement, Fun, Non-verbal, Conversation, Reminiscence, Confidence, Skills, } \\
\text { Surprise, Engagement, Enjoyment, Interaction, Confidence, Sensory. }\end{array}$ \\
\hline $\begin{array}{l}\text { Behrman et } \\
\text { al. (2014) }\end{array}$ & $\begin{array}{l}\text { Multi-sensory, Manage agitation, Orientation, Memory recall, Sense of } \\
\text { competency, Meaningful, Expressive, Emotional, Non-verbal, Tailored. }\end{array}$ \\
\hline $\begin{array}{l}\text { Byers } \\
(2011)\end{array}$ & $\begin{array}{l}\text { Untraditional, Aesthetic satisfaction, Creativity, Significance, Embodied, } \\
\text { Containment, Validation, Choice, Sensory, Product. }\end{array}$ \\
\hline $\begin{array}{l}\text { Caddell \& } \\
\text { Clare } \\
(2011)\end{array}$ & $\begin{array}{l}\text { Identity, Personhood, Independence, Remaining strengths, Self-esteem, } \\
\text { Socialisation, Expression, Spontaneity, Discussion, Reminiscence, Continuity, } \\
\text { Coherence, Multi-sensory, Existing relationships, Group, Individual, Tailored. }\end{array}$ \\
\hline $\begin{array}{l}\text { Coaten } \\
(2011)\end{array}$ & $\begin{array}{l}\text { Presence, Embodied, Accessing the world, Holistic, Non-verbal, Humour, Hope, } \\
\text { Training, Perception, Awareness, Identity, Integrity, Individualised, Creativity, } \\
\text { Experiential, Relationships, Trust, Energy, Adventure, Embrace difference, Group, } \\
\text { Individual, Reciprocal, Mutual, Multi-modal, Pleasure, Mirroring, Practicalities. }\end{array}$ \\
\hline $\begin{array}{l}\text { Cowl \& } \\
\text { Gaugler } \\
(2014)\end{array}$ & $\begin{array}{l}\text { Improving symptoms, Personal control, Social support, Meaningful relationships, } \\
\text { Carers, Mood, Communication, Engagement, Participation, Cognitive, } \\
\text { Engagement, Orientation, Participation, Pleasure, Relaxation, Self-esteem. }\end{array}$ \\
\hline $\begin{array}{l}\text { Crossick \& } \\
\text { Kaszynska } \\
(2016)\end{array}$ & $\begin{array}{l}\text { Carer involvement, Laughter, Participation, Knowledge of dementia, Imagination, } \\
\text { Interaction, Respect, Reduced stigma, Discussion, Relationships, Manage } \\
\text { symptoms, Cognitive ability, Memory, Achievement, Confidence, Skills, } \\
\text { Energised, Creativity, Engagement, Reminiscence. }\end{array}$ \\
\hline $\begin{array}{l}\text { deMedeiros } \\
\& \text { Basting } \\
(2013)\end{array}$ & $\begin{array}{l}\text { Behavioural changes, Tailored, Imagination, Stimulation, Reminiscence, } \\
\text { Validation, Emotional, Communication, Transformative, Meaningful. }\end{array}$ \\
\hline $\begin{array}{l}\text { Duffin } \\
(2013)\end{array}$ & $\begin{array}{l}\text { Reminiscence, Conversation, Humour, Non-verbal, Self-esteem, Overcome } \\
\text { isolation/unhappiness, Tailored, Skill sharing. }\end{array}$ \\
\hline $\begin{array}{l}\text { Habron } \\
(2013)\end{array}$ & $\begin{array}{l}\text { Supportive, Communication, Spontaneous, Creativity, Interactive, Enjoyment, } \\
\text { Emotional engagement, Cultural context, Resources, Participate, Validate, Flow, } \\
\text { Animation, Expression. }\end{array}$ \\
\hline
\end{tabular}




\begin{tabular}{|c|c|}
\hline $\begin{array}{l}\text { Hannemann } \\
(2006)\end{array}$ & $\begin{array}{l}\text { Stimulating, Potential, Sensory, Non-verbal, Reduce isolation, Perspective, Hope, } \\
\text { Spontaneity, Originality, Improvisation, Imagination, Creativity, Expression, Self- } \\
\text { knowledge, Integration, Inquisitiveness, Improvisation, Flexibility, Invigorate, } \\
\text { Heal, Connect, Intergenerational, Orientation, Self-confidence, Ownership of work, } \\
\text { Cultural awareness. }\end{array}$ \\
\hline $\begin{array}{l}\text { Holm et al. } \\
(2005)\end{array}$ & $\begin{array}{l}\text { Conversation, Stimulation, Identity, Integrity, Connectedness, Sharing, Express } \\
\text { feelings, Communication, Self-confidence, Courage, Memories, Involvement, } \\
\text { Curiosity, Address difficult subjects, Challenge, Fellowship. }\end{array}$ \\
\hline $\begin{array}{l}\text { Hulme et } \\
\text { al. (2010) }\end{array}$ & $\begin{array}{l}\text { Training, Carer inclusion, Manage behaviours, Socialisation, Problem solving, } \\
\text { Skills, Holistic, Orientation, Validation, Reminiscence, Instruction. }\end{array}$ \\
\hline $\begin{array}{l}\text { Jaaniste } \\
(2011)\end{array}$ & $\begin{array}{l}\text { Creativity, Fulfilment, Healing, Expression, Personal control, Role play, Growth, } \\
\text { Trust, Communication, Confidence, Improvisation, Play, Embodiment, Projection, } \\
\text { Storytelling, Humanity, Involvement, Curiosity, Non-verbal, Meaning, Aims, } \\
\text { Containment, Cognition, Freedom. }\end{array}$ \\
\hline $\begin{array}{l}\text { Killick \& } \\
\text { Allan } \\
(2011)\end{array}$ & $\begin{array}{l}\text { Purpose, Identity, Confidence, Creativity, Self-esteem, Personal control, Choice, } \\
\text { Positivity, Communication, Learning, Non-verbal, Sensory, Stimulate feelings, } \\
\text { Interpretation, Meaning, Individualised, The moment, Variety, Person-centred, } \\
\text { Relationships, Reflection, Reminiscence, Product, Imagination, Bonding, } \\
\text { Enjoyment, Ethical, Ownership of work, Equal worth, Interaction. }\end{array}$ \\
\hline $\begin{array}{l}\text { Kontos \& } \\
\text { Martin } \\
(2013)\end{array}$ & $\begin{array}{l}\text { Embodied, Power balance, Selfhood, Creativity, Subjectivity, Sensory, Agency, } \\
\text { Personhood, Training, Flexibility, Relationships, Personalization, Identity, } \\
\text { Socialization, Meaningful, Innovation, Non-verbal, Expression, Multi-modal, } \\
\text { Stimulation, Overcome isolation, Presence, Engagement, Recognise diversity. }\end{array}$ \\
\hline $\begin{array}{l}\text { Marshall \& } \\
\text { Hutchinson } \\
(2001)\end{array}$ & $\begin{array}{l}\text { Therapeutic, Stimulation, Self-esteem, Pleasure, Dignity, Meaningful, Restore } \\
\text { roles, Friendships, Cultural awareness and relevance, Accomplishment, } \\
\text { Contribution, Nourishment, Socialization, Conflict resolution, Pleasure, Dignity, } \\
\text { Familiarity, Reminiscence, Emotional expression, Skills. }\end{array}$ \\
\hline $\begin{array}{l}\text { Morley et } \\
\text { al. }(2014)\end{array}$ & $\begin{array}{l}\text { Meaningful, Enjoyable, Cognitive ability, Behaviour management, Discussion, } \\
\text { Training, Reminiscence, Task-oriented, Social stimulus, Gender specific. }\end{array}$ \\
\hline $\begin{array}{l}\text { Mottram } \\
(2003)\end{array}$ & $\begin{array}{l}\text { Diversion, Relaxation, Concentration, Self-esteem, Accessible, Expression, } \\
\text { Spontaneous, Communication, Trust, Relationship, Warmth, Empathy, Attentive, } \\
\text { Training, Cultural and contextual awareness, Sensitivity, Understanding, Dignity, } \\
\text { Empowerment, Engagement, Reminiscence, Individualized, Present, Potential. }\end{array}$ \\
\hline $\begin{array}{l}\text { Petrescu et } \\
\text { al. (2014) }\end{array}$ & $\begin{array}{l}\text { Contribution, Catharsis, Personhood, Stimulating, Inspiration, Sociability, } \\
\text { Expression, Purpose, Stories, Selfhood, Engagement, Challenge, Skill sharing. }\end{array}$ \\
\hline $\begin{array}{l}\text { Phillips \& } \\
\text { Conn } \\
(2009)\end{array}$ & $\begin{array}{l}\text { Reduce symptoms, Creative, Participation, Product, Perspective, Skills, Self- } \\
\text { expression, Process, Communication, Sensory, Emotional relief, Failure-free, Non- } \\
\text { verbal, Reminiscence, Positive feelings, Person-centred, Tailored, Engagement. }\end{array}$ \\
\hline $\begin{array}{l}\text { Price \& } \\
\text { Tinker } \\
(2014)\end{array}$ & $\begin{array}{l}\text { Interaction, Cognitive stimulation, Self-worth, Innovation, Quality, Achievement, } \\
\text { Appropriateness, Interpretation, Reflection, Motivation, Expression, Confidence, } \\
\text { Skills, Acknowledge the future, Purpose, Structure, Intergenerational, Community } \\
\text { cohesion, Accessibility, Engagement, Relaxation, Emotion. }\end{array}$ \\
\hline
\end{tabular}




\begin{tabular}{|c|c|}
\hline $\begin{array}{l}\text { Rancour \& } \\
\text { Barrett } \\
(2011)\end{array}$ & $\begin{array}{l}\text { Connection, Expression, Communication, Teach, Presence, Empathy, } \\
\text { Empowerment, Holistic, Interpretation, Restoration, Learning, Hope, Respect, } \\
\text { Experimentation, Listening, Identity, Meaning, Reflection, Non-verbal, Choice, } \\
\text { Potential, Community. }\end{array}$ \\
\hline $\begin{array}{l}\text { Rylatt } \\
(2012)\end{array}$ & $\begin{array}{l}\text { Expression, Communication, Pleasure, Enjoyment, Engagement, Multi-sensory, } \\
\text { Self-esteem, Mood, Skills, Reminiscence, Resilience, Training, Multi-modal, } \\
\text { Observation, Non-verbal, Embodiment. }\end{array}$ \\
\hline $\begin{array}{l}\text { Sixsmith \& } \\
\text { Gibson } \\
(2007)\end{array}$ & $\begin{array}{l}\text { Participation, Enjoyment, Meaningful, Social cohesion, Empowerment, Self- } \\
\text { esteem, Independent, Interaction, Exploration, Identity, Spirituality, Reminiscence, } \\
\text { Preserve ability, Manage behaviours, Expression, Stimulation, Pleasure, Soothing, } \\
\text { Uplifting, Sharing, Accessibility, Choice, Freedom, Continuation. }\end{array}$ \\
\hline $\begin{array}{l}\text { Solé et al. } \\
(2014)\end{array}$ & $\begin{array}{l}\text { Tailored, Cognitive stimulation, Mood, Self-esteem, Participation, Entertainment, } \\
\text { Spirituality, Development, Fulfilment, Happiness, Relaxation, Improvisation, Fun, } \\
\text { Discussion, Expression, Failure-free. }\end{array}$ \\
\hline $\begin{array}{l}\text { Spitzer } \\
(2011)\end{array}$ & $\begin{array}{l}\text { Humour, Laughter, Morale, Play, Interaction, Professionalism, Quality, Enjoyment, } \\
\text { Reduced symptoms, Tailored, Flexibility, Multi-modal, Reduce isolation, Balanced } \\
\text { power, Supportive, Training. }\end{array}$ \\
\hline $\begin{array}{l}\text { Stevens } \\
(2011)\end{array}$ & $\begin{array}{l}\text { Humour, Improvisation, Creating, Learning, Sociability, Self-esteem, Resilience, } \\
\text { Interpersonal skills, Relationships, Active, Empathy, Cognition, Carer involvement, } \\
\text { Surprise, Recognising potential, The moment, Respect, Cohesion, Therapeutic. }\end{array}$ \\
\hline $\begin{array}{l}\text { Tuppen } \\
(2012)\end{array}$ & $\begin{array}{l}\text { Multi-modal, Cognitive stimulation, Potential, Relationships, No stigma, Tailored, } \\
\text { Skills, Reminiscence, Orientation, Training, Discussion, Accessibility, } \\
\text { Communication, Enjoyment, Mood, Fun, Normalizing, Reduce isolation. }\end{array}$ \\
\hline $\begin{array}{l}\text { Ullán et al. } \\
\text { (2013) }\end{array}$ & $\begin{array}{l}\text { Tailored, Education, Satisfaction, Process, Positive image, Creativity, Enjoyment, } \\
\text { Communication, Citizenship, Aesthetic, Participation, Personal value, Identity, } \\
\text { Doing, Product, Newness, Failure-free, Engagement, Training, Relationships, } \\
\text { Validation, Reflection. }\end{array}$ \\
\hline $\begin{array}{l}\text { Vella- } \\
\text { Burrows \& } \\
\text { Wilson } \\
(2016)\end{array}$ & $\begin{array}{l}\text { Dignity, Autonomy, Meaning, Participation, Enjoyment, Purpose, Joy, Cultural, } \\
\text { Achievement, Creativity, Learning, Communication, Manage symptoms, Fun, Co- } \\
\text { operation, Expression, Friendship, Hope, Community, Non-competitive, Discovery, } \\
\text { Embodiment, Flow, Presence, Multi-modal, Aliveness, Relaxing. Self-esteem. }\end{array}$ \\
\hline $\begin{array}{l}\text { Verity \& } \\
\text { Lee }(2011)\end{array}$ & $\begin{array}{l}\text { Energy, Positivity, Intuition, Interaction, Open-mindedness, Potential, Enrichment, } \\
\text { Self-esteem, Confidence, Communication, Skills, Vitality, Orientation, Humour, } \\
\text { Playful, No stigma, Training, Cultural awareness, Education, Spontaneous, } \\
\text { Transformation. }\end{array}$ \\
\hline $\begin{array}{l}\text { Windle et } \\
\text { al. (2014) }\end{array}$ & $\begin{array}{l}\text { Context, Participation, Personal value, Purpose, Cognitive function, Creativity, } \\
\text { Communication, Reminiscence, Meaningful, Self-esteem, Carer impact, Reflective } \\
\text { practice, Relationships, Knowledge, Identity, Non-verbal, Happiness. }\end{array}$ \\
\hline $\begin{array}{l}\text { Woods \& } \\
\text { Jury }(2010)\end{array}$ & $\begin{array}{l}\text { Continuation, Multi-modal, Recollection, Purposeful, Meaningful, Quality, Sense } \\
\text { of control, Fluid, Training, Accessibility. }\end{array}$ \\
\hline $\begin{array}{l}\text { Zeiler } \\
(2014)\end{array}$ & $\begin{array}{l}\text { Embodiment, Personhood, Mutuality, Reciprocity, Improvisation, Involvement, } \\
\text { Reduce isolation, Expression, Enabling, Interaction, Openness, Co-ordination, } \\
\text { Engagement, Attunement, Responsive, Belonging, Quality. }\end{array}$ \\
\hline
\end{tabular}


Zinn (2005) Purposeful, Tailored, Meaningful, Helping others, Therapeutic, Cognition,

Familiarity, Failure-free, Enjoyment, Process, Choice, Individualized, Repetition,

Potential, Spontaneous, Encouragement, Engagement, Sensory, Pleasure. 
Table 3: Stakeholder identities of focus group and NGT workshop participants

\begin{tabular}{|l|}
\hline \multicolumn{1}{|c|}{ Focus group 1 } \\
\hline Arts manager \\
\hline Artist \\
\hline Arts practitioner \\
\hline Care home activity co-ordinator \\
\hline Care home manager \\
\hline Care home activity co-ordinator \\
\hline Arts researcher \\
\hline Art gallery community programmer \\
\hline
\end{tabular}

\begin{tabular}{|l|}
\hline \multicolumn{1}{|c|}{ Focus group 2} \\
\hline Carer, Father with dementia \\
\hline Carer, Father-in-law with dementia \\
\hline Carer, Mother-in-law with dementia, sings in care \\
\hline Carer, both parents with dementia \\
\hline Carer, both parents with dementia \\
\hline Ex-carer, singing intervention volunteer \\
\hline Carer, arts session leader \\
\hline Person with dementia \\
\hline
\end{tabular}

\begin{tabular}{|l|}
\hline Focus group 3 \\
\hline Musician, parent with dementia \\
\hline
\end{tabular}


Arts practitioner

Writer and Theatre Director

Arts lecturer, shared reading session leader

Musician, care staff trainer, parent with dementia

\begin{tabular}{|l|}
\hline \multicolumn{1}{|c|}{ NGT workshop 1 } \\
\hline Carer, Father with dementia \\
\hline Carer, Father with dementia \\
\hline Carer, Mother with dementia \\
\hline Carer, Spouse with dementia \\
\hline
\end{tabular}

\begin{tabular}{|l|}
\hline \multicolumn{1}{|c|}{ NGT workshop 2 } \\
\hline Musician, parent with dementia \\
\hline Project manager for arts and dementia programme \\
\hline Researcher \\
\hline Arts workshop facilitator for people with dementia, \\
\hline Writer and Theatre Director \\
\hline Musician, working with people with dementia \\
\hline Manager of arts and dementia organisation, carer of \\
parent with dementia \\
\hline Carer, parents with dementia \\
\hline Musician, care staff trainer, parent with dementia \\
\hline Music practitioner, researcher \\
\hline
\end{tabular}


Table 4: Principles of arts interventions and summaries

\begin{tabular}{|c|c|}
\hline Principle & Summary \\
\hline Animation & $\begin{array}{l}\text { An arts intervention engages and stimulates, possibly } \\
\text { using improvisation or play, and gives participants an } \\
\text { opportunity to take part in a live activity themselves. }\end{array}$ \\
\hline Transcendence & $\begin{array}{l}\text { An arts intervention might transform its participants using } \\
\text { creativity, imagination and flow - transporting them to a } \\
\text { different time, emotional space or bringing them into the } \\
\text { moment. }\end{array}$ \\
\hline Selfhood & $\begin{array}{l}\text { An arts intervention can offer a sense of purpose that } \\
\text { supports feelings of independence and empowerment, } \\
\text { while being personalised and relevant to individual needs } \\
\text { and choices. }\end{array}$ \\
\hline Humanity & $\begin{array}{l}\text { An arts intervention can empathise, validate and stabilise } \\
\text { mood, enabling a process of healing, trust and hope which } \\
\text { might support a sense of embodiment. }\end{array}$ \\
\hline Expression & $\begin{array}{l}\text { An arts intervention allows participants to communicate } \\
\text { their emotions, sometimes without language, generating } \\
\text { enjoyment, discussion or challenge to make collective } \\
\text { and individual meaning through participation. }\end{array}$ \\
\hline Connection & $\begin{array}{l}\text { An arts intervention can facilitate connection to the self } \\
\text { and others through bonding, morale and reminiscence, } \\
\text { enabling social interaction and relationship building } \\
\text { which might result in a sense of community. }\end{array}$ \\
\hline Possibility & $\begin{array}{l}\text { An arts intervention can enable achievement, learning and } \\
\text { the development of skills in a failure free environment, } \\
\text { which encourages curiosity and provides a focus on } \\
\text { growth enrichment and potential. }\end{array}$ \\
\hline Involvement & $\begin{array}{l}\text { An arts intervention is welcoming, inclusive, mutual and } \\
\text { equalizing, encompassing a range of limitless activities } \\
\text { that help to embed the arts into everyday life. }\end{array}$ \\
\hline Awareness & $\begin{array}{l}\text { An arts intervention is reflective, does not cause harm and } \\
\text { is responsive to different personal reactions, while } \\
\text { engaging with the outside world in a way that takes } \\
\text { account of its diversity. }\end{array}$ \\
\hline
\end{tabular}


Table 5: Principles and descriptive features of arts interventions

\begin{tabular}{|c|c|c|}
\hline Principle & \multicolumn{2}{|c|}{ Features of principle } \\
\hline \multirow[t]{5}{*}{ Animation } & Surprise & Improvisation \\
\hline & Play & Joy \\
\hline & Stimulation & Energy \\
\hline & Activity & Humour \\
\hline & Spontaneity & Engagement \\
\hline \multirow[t]{5}{*}{ Transcendence } & Aesthetics & Imagination \\
\hline & Creativity & Flow \\
\hline & Spiritual & Multi-modal \\
\hline & Transformative & Entrainment \\
\hline & Moment & Multi-reality \\
\hline \multirow[t]{5}{*}{ Selfhood } & Purpose & Independence \\
\hline & Relevance & Accessibility \\
\hline & Self-esteem & Personalisation \\
\hline & Dignity & Choice \\
\hline & Flexible & Empowerment \\
\hline \multirow[t]{5}{*}{ Humanity } & Hope & Supportive \\
\hline & Embodiment & Healing \\
\hline & Mood & Empathy \\
\hline & Validation & Process \\
\hline & Liberate & Trust \\
\hline Expression & Non-verbal & Enjoyment \\
\hline
\end{tabular}




\begin{tabular}{|c|c|c|}
\hline & Worthwhile & Participation \\
\hline & Subjectivity & Making meaning \\
\hline & Communication & Emotions \\
\hline & Discussion & Challenge \\
\hline Connection & Community & Intergenerational \\
\hline & Partnership & Relationship \\
\hline & Respect & Bonding \\
\hline & Friendship & Interaction \\
\hline & Reminiscence & Morale \\
\hline Possibility & Skills & Strengths \\
\hline & Product & Enrichment \\
\hline & Potential & Achievement \\
\hline & Curiosity & Learning \\
\hline & Failure free & Growth \\
\hline Involvement & Integration & Equalising \\
\hline & Co-production & Normalising \\
\hline & Limitless & Open minded \\
\hline & Embedded & Mutuality \\
\hline & Welcoming & Colleagues \\
\hline Awareness & Quality & Reflection \\
\hline & Practicality & Authenticity \\
\hline & Courage & Reaction \\
\hline & Diversity & External \\
\hline & Responsive & Harmless \\
\hline
\end{tabular}




\section{Figure captions}

Figure 1: Flow diagram showing selection of literature

\section{1 articles screened from 4 databases}

Duplicates (725) and

irrelevant references removed

748 articles remaining

Application of research question inclusion criteria

29 articles remaining

Inclusion of 9 additional sources

Total: 38 sources for literature review 